\title{
Least Squares 3D Algorithm for the Study of Deformations with Terrestrial Laser Scanner
}

\author{
Vincenzo Barrile, Giuseppe M. Meduri \\ Dept. DICEAM, Faculty of Engineering \\ Mediterranean University of Reggio Calabria \\ Reggio Calabria, Italy \\ vincenzo.barrile@unirc.it, giumed@libero.it
}

\author{
Giuliana Bilotta \\ Dept. of Planning, Ph.D. NT\&ITA \\ University IUAV of Venice \\ Venice, Italy \\ giuliana.bilotta@gmail.com
}

Received: March 20, 2021. Revised: April 19, 2021. Accepted: April 22, 2021. Published: April 28, 2021.

\begin{abstract}
The application in question is aimed, in the study of deformations of mountain areas, as well as test the TLS applied to a hilly area in two different eras. For this purpose, it was also tested using the algorithm LS3D "Least square 3D surface matching" that allows both the registration of point clouds produced by scans carried out without using targets but, overall, the estimate of deformations that in this case, compared to other methods, is done directly on the basis of the two data sets acquired in two different periods of time $t_{1}$ and $t_{2}$.
\end{abstract}

Keywords- Laser scanner 3D; Least square 3D surface matching; TLS; 3D modelization; Survey; Radiometric data.

\section{INTRODUCTION AND STUDY AREA}

The Faculty of Agriculture of the University "Mediterranea" of Reggio Calabria is built on a hill that offers a specific geomorphology. In fact, after the construction of the Faculty building some problems arose, regarding its stability, the possible deformations through time also because of poor vegetation.

The Laboratory of Geomatics Engineering Faculty of the University "Mediterranea" of Reggio Calabria, used Terrestrial Laser Scanner for monitoring the hill, doing the scans after three years and examining the results obtained. Every era we made two scans, that we found to be sufficient to cover the entire study area.

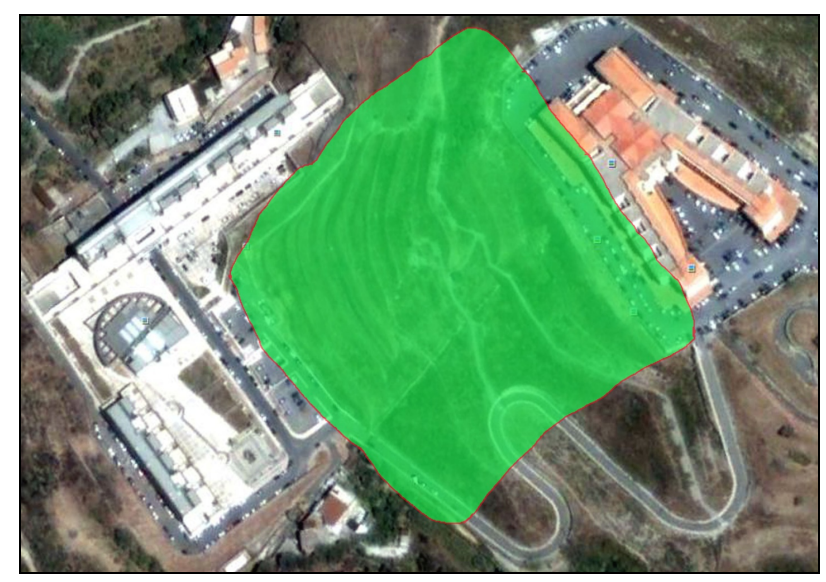

Fig. 1. Study area.

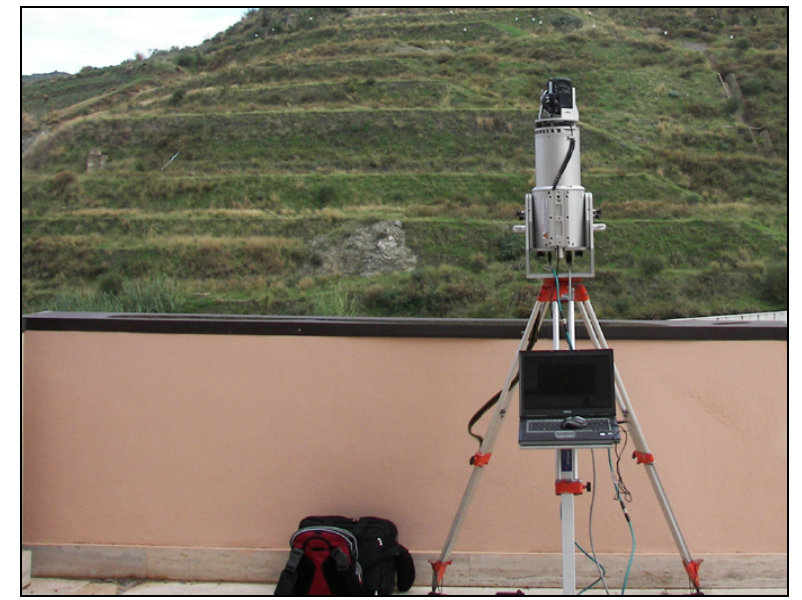

Fig. 2. A view of the scanner.

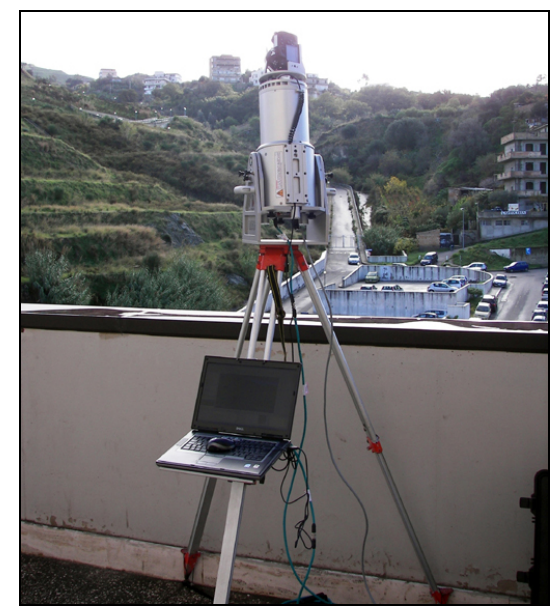

Fig. 3. Some views of the scans.

\section{REGISTRATIONS OF THE SCANS}

The first operation performed after the relief phase was therefore recording different scans with a procedure based on the algorithm of "Least Squares 3D surface matching" without the need of using targets in data processing, however, present during scanning. 


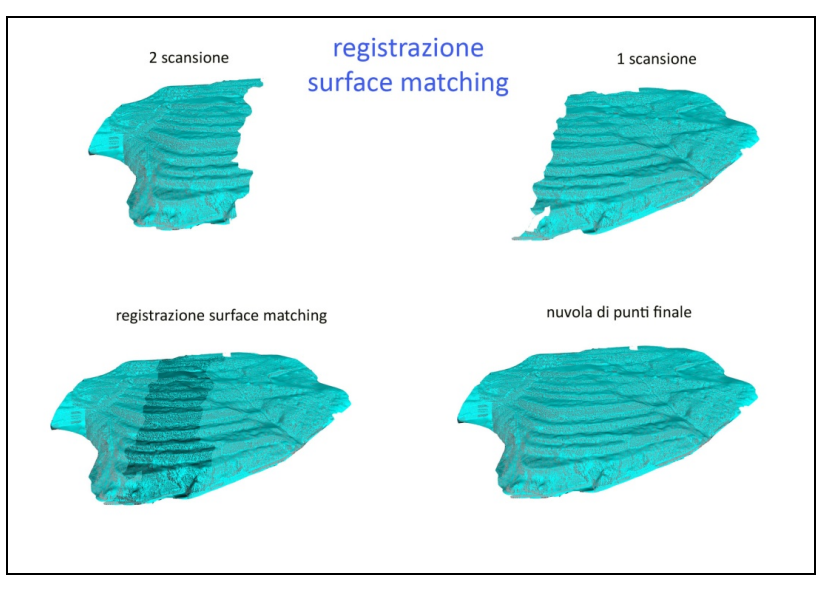

Fig. 4. Schematization of the surface matching with LS3D.

The recording of the entire cloud at each epoch is done so by applying a global matching. The mathematical model used considers the reflection that, at every point of the first surface $f_{(\mathrm{x}, \mathrm{y}, \mathrm{z})}$ has an exact match with $g_{(\mathrm{x}, \mathrm{y}, \mathrm{z})}$ and with $e_{(\mathrm{x}, \mathrm{y}, \mathrm{z})}$ the error vector (random errors).

The matching is obtained by the least squares objective function that represents the sum of squared Euclidean distances between the two surfaces.

$$
\sum\|\vec{d}\|^{2}=\min
$$

TABLE I.

\begin{tabular}{|c|c|c|c|c|c|c|c|c|}
\hline No & $\begin{array}{c}\text { TMP } \\
\text { scan } \\
\text { no } \\
(\#)\end{array}$ & $\begin{array}{c}\text { SRC } \\
\text { scan } \\
\text { no } \\
(\#)\end{array}$ & $\begin{array}{c}\text { No.of } \\
\text { TMP } \\
\text { points } \\
(\mathbf{K})\end{array}$ & $\begin{array}{c}\text { No.of } \\
\text { SRC } \\
\text { points } \\
\text { (K) }\end{array}$ & $\begin{array}{c}\text { No. of } \\
\text { COR } \\
\text { points } \\
\text { (K) }\end{array}$ & Inter. & $\begin{array}{c}\text { Time } \\
\text { (sec) }\end{array}$ & $\begin{array}{c}\text { Sigma } \\
\text { naught } \\
\text { (cm) }\end{array}$ \\
\hline 1 & 1 & 2 & 2063 & 2008 & 1376 & 3 & 1324 & 0,3 \\
\hline
\end{tabular}

a. Numerical results of the "surface matching" LS3D with the two clouds of point at the

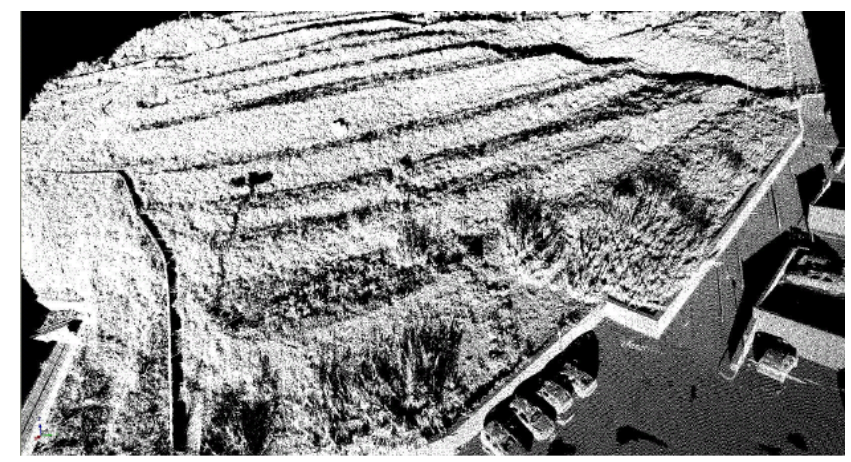

Fig. 5. Global cloud of points cleaned after the recording with LS3D of the scan at the time $\mathrm{t}_{1}$.

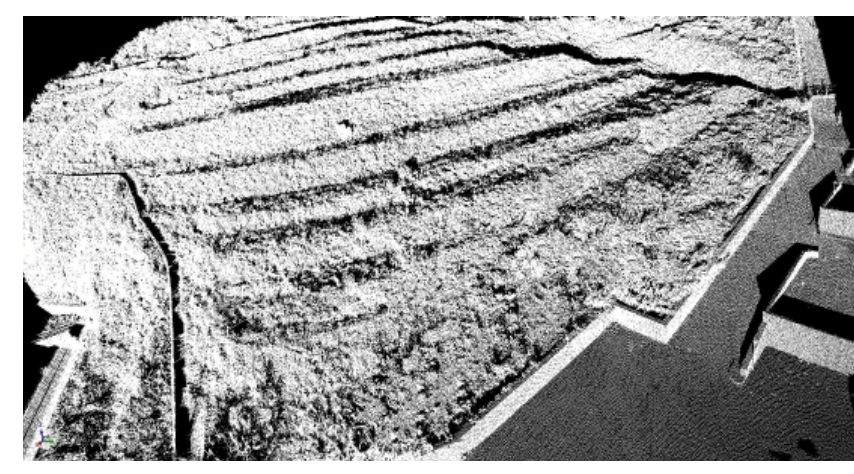

Fig. 6. Global cloud of points cleaned after the recording with LS3D of the scan at the time $t_{2}$.

TABLE II.

\begin{tabular}{|c|c|c|c|c|c|c|c|c|}
\hline No & $\begin{array}{c}\text { TMP } \\
\text { scan } \\
\text { no } \\
(\#)\end{array}$ & $\begin{array}{c}\text { SRC } \\
\text { scan } \\
\text { no } \\
(\#)\end{array}$ & $\begin{array}{c}\text { No.of } \\
\text { TMP } \\
\text { points } \\
(\mathbf{K})\end{array}$ & $\begin{array}{c}\text { No.of } \\
\text { SRC } \\
\text { points } \\
(\mathbf{K})\end{array}$ & $\begin{array}{c}\text { No. of } \\
\text { COR } \\
\text { points } \\
\text { (K) }\end{array}$ & Inter. & $\begin{array}{c}\text { Time } \\
\text { (sec) }\end{array}$ & $\begin{array}{c}\text { Sigma } \\
\text { naught } \\
(\mathbf{c m})\end{array}$ \\
\hline 1 & 1 & 2 & 1978 & 2043 & 1412 & 3 & 1342 & 0,3 \\
\hline
\end{tabular}

The matching for the registration of the whole cloud at the epochs $t_{1}$ and $t_{2}$ presupposes the selection of three points in common on the scans to be joined; by applying the matching several times using different homologous points, the results were validated using the statistical test $\chi^{2}$.

The variable $\chi^{2}$ measures the overall difference between observed and expected data according expression:

$$
\begin{aligned}
& \chi^{2}=\sum_{i=1}^{N} \frac{\left(f_{O i}-f_{A i}\right)^{2}}{f_{A i}} \\
& \quad \text { The test } \chi^{2}\left(p_{1}, \alpha\right)<\chi^{2}<\chi^{2}\left(p_{2}, \alpha\right) \text { for a risk of } \\
& \text { error } \alpha \text { equal to } 5 \% \text { is verified result. }
\end{aligned}
$$

\section{SUBSEQUENT PROCESSING - CONTROL OF DEFORMATION}

Once registered scans for the generation of clouds at two times $t_{1}$ and $t_{2}$, the "global matching" is re-applied to monitor the deformation.

The procedure involves three steps:

- global matching of the two point clouds over the area selected as stable;

- global matching of all points of the clouds over an area already found stable and searching for areas of possible movement;

- local matching of selected areas to estimate the deformation. 
In the first step the algorithm LS3D is applied to areas that we assume as stable, eliminating areas with possible movements; the two clouds (registered) at the two epochs are traced thus in a common reference system.

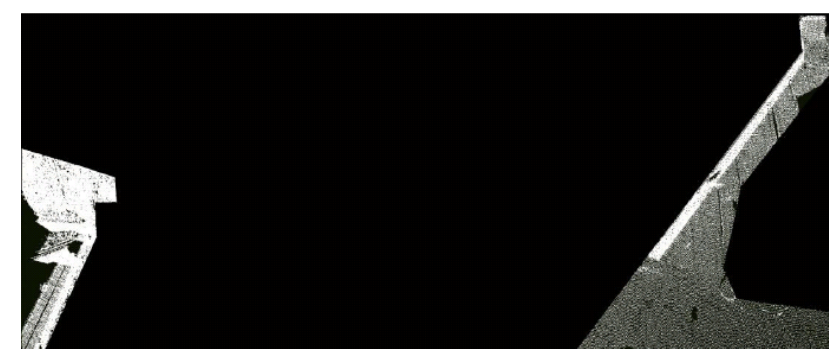

Fig. 7. Stable area chosen for the global "matching".

TABLE III.

\begin{tabular}{|c|c|c|c|c|c|c|c|c|}
\hline No & $\begin{array}{c}\text { TMP } \\
\text { scan } \\
\text { no } \\
\text { (\#) }\end{array}$ & $\begin{array}{c}\text { SRC } \\
\text { scan } \\
\text { no } \\
\text { (\#) }\end{array}$ & $\begin{array}{c}\text { No.of } \\
\text { TMP } \\
\text { points } \\
\text { (K) }\end{array}$ & $\begin{array}{c}\text { No.of } \\
\text { SRC } \\
\text { points } \\
\text { (K) }\end{array}$ & $\begin{array}{c}\text { No. of } \\
\text { COR } \\
\text { points } \\
\text { (K) }\end{array}$ & Inter. & $\begin{array}{c}\text { Time } \\
\text { (sec) }\end{array}$ & $\begin{array}{c}\text { Sigma } \\
\text { naught } \\
\text { (cm) }\end{array}$ \\
\hline 1 & 1 & 2 & 487 & 486 & 486 & 2 & 303 & 0,3 \\
\hline
\end{tabular}

Numerical results of the "global matching" of the clouds of point at the time $\mathrm{t} 1$ and $\mathrm{t} 2$.

The second step is based on the same matching technique, but drawing the two point clouds, already traced in the same reference system, and considering whole clouds, therefore not only stable areas but also the areas with possible movements.

TABLE IV.

\begin{tabular}{|c|c|c|c|c|c|c|c|c|}
\hline No & $\begin{array}{c}\text { TMP } \\
\text { scan } \\
\text { no } \\
(\#)\end{array}$ & $\begin{array}{c}\text { SRC } \\
\text { scan } \\
\text { no } \\
(\#)\end{array}$ & $\begin{array}{c}\text { No.of } \\
\text { TMP } \\
\text { points } \\
(\mathbf{K})\end{array}$ & $\begin{array}{c}\text { No.of } \\
\text { SRC } \\
\text { points } \\
(\mathbf{K})\end{array}$ & $\begin{array}{c}\text { No. of } \\
\text { COR } \\
\text { points } \\
(\mathbf{K})\end{array}$ & Inter. & $\begin{array}{c}\text { Time } \\
\text { (sec) }\end{array}$ & $\begin{array}{c}\text { Sigma } \\
\text { naught } \\
\text { (cm) }\end{array}$ \\
\hline 1 & 1 & 2 & 2695 & 2609 & 2543 & 3 & 1793 & 0,25 \\
\hline
\end{tabular}

Global matching" considering the stable areas and those with possible movements.
To improve the reliability of the results obtained have been made more cycles of local "matching" and validating the results obtained through statistical tests.

The value of the Student's $t$ test is calculated as the ratio of the observed mean difference and its standard error

$t=\bar{d} / \sqrt{\left(S_{d}^{2} / n\right)}$

where:

$\bar{d}=\sum d_{i} / n$ with $d_{i}$ difference between the pairs of results obtained

$S_{d}^{2}=\sum\left(d_{i}-d\right)^{2} /(n-1)$

The last stage of the method consists in the estimation of relative movement to some portions of the hill using the same method but using LS3D local matches in a "local matching". Selected portions for analysis, for each "patch" on the cloud at the time $t_{1}$ is automatically detected by the subset corresponding LS3D the cloud at the time $t_{2}$, thus obtaining the seven transformation parameters that describe the deformation and, in particular, the three translations and the three rotations.

TABLE V.

\begin{tabular}{|c|r|r|r|}
\hline $\begin{array}{c}\text { Deformation } \\
\text { parameters }\end{array}$ & Unit & Cockpit & Rock \\
\hline$t_{x}$ & $\mathrm{~cm}$ & 0,11 & 0,32 \\
\hline$t_{y}$ & $\mathrm{~cm}$ & 0,32 & 0,29 \\
\hline$t_{\boldsymbol{z}}$ & $\mathrm{cm}$ & $-0,26$ & $-0,52$ \\
\hline$\omega$ & gon & 0,2 & 0,1 \\
\hline $\boldsymbol{\omega}$ & gon & 0,1 & 0,05 \\
\hline $\boldsymbol{K}$ & gon & 0,09 & 0,07 \\
\hline $\boldsymbol{m}$ & $\begin{array}{c}\text { Pure } \\
\text { number }\end{array}$ & 1 & 1 \\
\hline
\end{tabular}

Results of monitoring of deformations of the two regions examined with LS3D (shifts measured in centimeters and rotations in gons ( 1 circle 400gons)

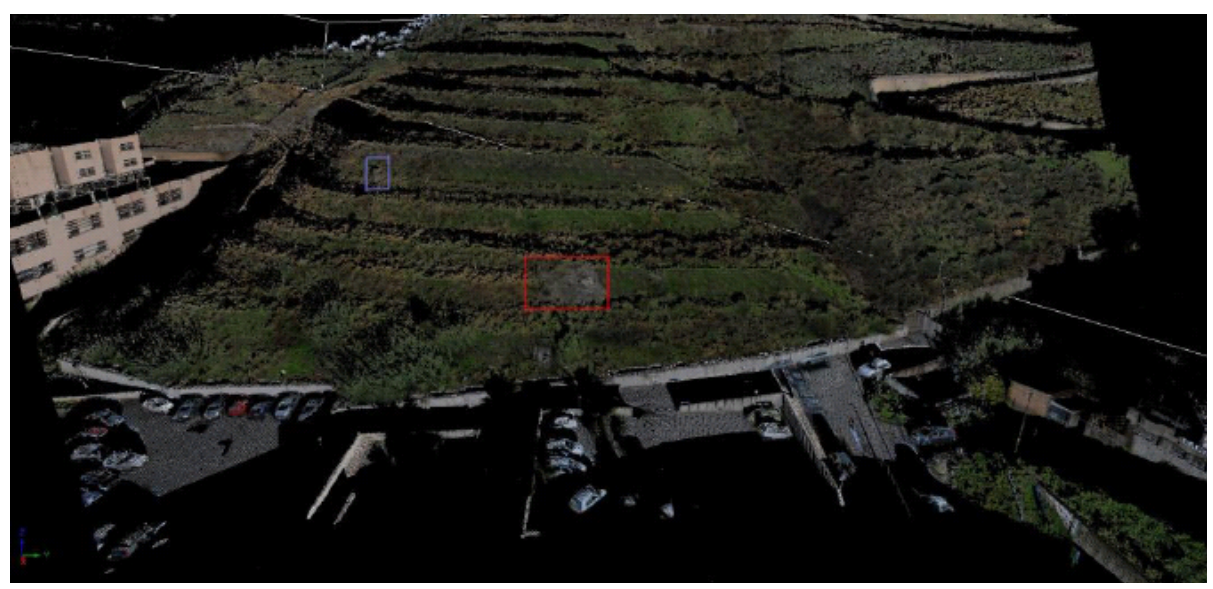

Fig. 8. The areas chosen for the control of the deformations. 


\section{CONCLUSION}

The experience carried out has highlighted the benefits of LS3D than other methods. The first is to exploit all the information provided by the geometry of the 3D cloud of points to be able to measure strain with a magnitude less than the accuracy of the instrument. The second is to implement a flexible procedure that can be applied with any type of scenes including a wide range of applications of deformation. The third is to measure movement in three dimensions, not only along a preferred direction.

\section{REFERENCES}

[1] P.J. Besl, N.D. McKay, "A method for registration of 3-D shapes", in IEEE Transactions on Pattern Analysis and Machine Intelligence, vol. 14, issue 2, 1992, pp. 239-256.

[2] B. Crippa, "Computational algorithms and optimal procedures for the digital terrain models production", in Bollettino di Geodesia e Scienze Affini, vol. 1, 1991, pp. 11-30.
[3] J. Gomes Mota, "Localisation of Mobile Robots using Scanned Laser and Reconstructed 3D Models", MSc Thesis, Instituto Superior Técnico, Universidade Técnica de Lisboa, Portugal, May 2002.

[4] S.J. Gordon, D.D. Lichti, "Terrestrial laser scanners with a narrow field of view: the effect on 3D resection solutions", in Survey Review, vol. 37 , issue 292, 2004, pp. 448-468.

[5] A. Gruen, A. Devrim, "Least squares 3D surface and curve matching", in ISPRS Journal of Photogrammetry and Remote Sensing, vol. 59, issue 3, 2005, pp. 151-174.

[6] O. Monserrat, M. Crosetto, "Deformation measurement using terrestrial laser scanning data and least squares 3D surface matching", in ISPRS Journal of Photogrammetry and Remote Sensing, vol. 63, issue 1, January 2008, pp. 142-154.

[7] 4DiXplorer AG LS3D User guide.

\section{Creative Commons Attribution License 4.0 (Attribution 4.0 International, CC BY 4.0)}

This article is published under the terms of the Creative Commons Attribution License 4.0

https://creativecommons.org/licenses/by/4.0/deed.en US 